\title{
O dito e o não dito no ensino das infecções sexualmente transmissiveis
}

The said and the unsaid in the teaching of sexually transmitted infections Lo que se dice y lo que no se dice en la enseñanza de infecciones de transmisión sexual

\author{
Stéfany Petry ${ }^{1} \mathbb{D}$ nttps://orcid.org/0000-0001-9713-247X \\ Maria Itayra Padiliha ${ }^{1,2}$ \& https://orcid. org/0000-0001-9695-640X \\ Maria Lígia dos Reis Bellaguarda1 ${ }^{1}$ ic https://orcid.org/0000-0001-9998-3040 \\ Amanda Nicácio Vieira ${ }^{1}$ io https://orcid.org/0000-0002-6743-2575 \\ Vanessa Ribeiro Neves² ${ }^{2}$ https://orcid.org/0000-0002-2226-4723
}

Como citar:

Petry S, Padilha MI, Bellaguarda ML, Vieira AN, Neves VR. 0 dito e o não dito no ensino das infecções sexualmente transmissiveis. Acta Paul Enferm. 2021;34:APE001855.

DOI

http://dx.doi.org/10.37689/actaape/2021A0001855

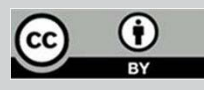

Descritores

Educação em enfermagem; Doenças sexualmente transmissíveis; Docentes; Estudantes de enfermagem; Populações vulneráveis

Keywords

Education, nursing; Sexually transmitted diseases; Faculty; Students, nursing; Vulnerable populations

Descriptores Educación en enfermeira; Enfermedades de transmisión sexual; Docentes; Estudiantes de

enfermeira;

Poblaciones vulnerables

Submetido

15 de Julho de 2020

Aceito

5 de Março de 2021

Autor correspondente

Stéfany Petry

E-mail: stefanypetry@hotmail.com

\section{Resumo}

Objetivo: Analisar o dito e o não dito no ensino das Infecções Sexualmente Transmissíveis em um Curso de Graduação em Enfermagem do Sul do Brasil.

Métodos: Pesquisa qualitativa, de cunho histórico-social, com uso de fontes orais e documentais. As fontes orais foram 13 docentes do curso e as documentais foram Catálogos Oficiais produzidos pela instituição, Projeto Político Pedagógico disponíveis online e planos de ensino de disciplinas. A coleta de dados ocorreu entre dezembro de 2018 e abril de 2019. A análise dos dados foi fundamentada na proposta operativa de Minayo e discutida através do referencial teórico da Vulnerabilidade.

Resultados: Emergiram três categorias de análise (Des)preparo do docente e dos profissionais de saúde para lidar com o tema; (Des)preparo dos estudantes acerca da própria vulnerabilidade às Infecções Sexualmente Transmissíveis; Enfoque do currículo do curso de enfermagem com as populações vulneráveis. 0 ensino da sexualidade, infecções sexualmente transmissíveis e populações vulneráveis foi evidenciado como tópico que envolve muitas dificuldades ainda associadas a tabus e estigmas. Existe uma preocupação com relação ao preparo do docente, como também com os futuros profissionais de saúde e sua atuação nos campos de prática. Os estudantes de enfermagem não percebem a própria vulnerabilidade e suas dificuldades diante da aproximação de grupos vulneráveis durante o processo formativo.

Conclusão: Aspectos relativos à sexualidade, infecções sexualmente transmissiveis e às populações vulneráveis estão presentes no ensino e na prática profissional em enfermagem. Esses tópicos respondem a necessidade da sociedade e a importância em intervir e refletir sobre os mesmos.

\section{Abstract}

Objective: To analyze the said and the unsaid in the teaching of Sexually Transmitted Infections in an Undergraduate Nursing Course in the South Region of Brazil.

Methods: Social-historical research with a qualitative approach, using oral and documentary sources. The oral sources were 13 professors of the course and the documentary sources were Official Catalogs produced by the institution, the Political Pedagogical Project available online and the teaching plans of the disciplines. Data was collected from December 2018 to April 2019. Data analysis was based on Minayo's operational proposal and discussed through the theoretical framework of Vulnerability.

Results: Three categories of analysis emerged: Professors' and health professionals' preparation, or lack thereof, for dealing with the subject; Students' preparation, or lack thereof, for their own vulnerability to Sexually Transmitted Infections; Focus on vulnerable populations in the curriculum of the nursing course. The teaching of sexual education, sexually transmitted infections and vulnerable populations was highlighted as 
a topic that involves many difficulties and is still associated with taboos and stigma. There is a concern regarding the preparation of the professor, as well as the future health professionals and their professional practice in the area. Nursing students do not perceive their own vulnerability and difficulties towards the approach of vulnerable groups during the training process.

Conclusion: Aspects related to sexuality, sexually transmitted infections and vulnerable populations are present in teaching and professional nursing practice. These topics are a response to the needs of society and to the importance of intervening and reflecting on these issues.

\section{Resumen}

Objetivo: Analizar lo que se dice y lo que no se dice en la enseñanza de infecciones de transmisión sexual en una carrera de grado de enfermería en la región Sur de Brasil.

Métodos: Estudio cualitativo, de carácter histórico-social, con uso de fuentes orales y documentales. Las fuentes orales fueron 13 docentes de la carrera y las documentales fueron catálogos oficiales producidos por la institución, Proyecto Político Pedagógico, disponibles de forma digital y programas de estudio de las disciplinas. La recopilación de datos se realizó entre diciembre de 2018 y abril de 2019. El análisis de los datos se basó en la propuesta operativa de Minayo y se discutió mediante el marco referencial teórico de la vulnerabilidad.

Resultados: Surgieron tres categorías de análisis: (Falta de)preparación del docente y de los profesionales de la salud para lidiar con el tema, (Falta de) preparación de los estudiantes acerca de la propia vulnerabilidad hacia las infecciones de transmisión sexual y Enfoque del diseño curricular de la carrera de enfermería respecto a las poblaciones vulnerables. La enseñanza de la sexualidad, de infecciones de transmisión sexual y de poblaciones vulnerables fue identificado como un tema que incluye muchas dificultades aún relacionadas con tabús y estigmas. Existe una preocupación con relación a la preparación del docente, como también con los futuros profesionales de la salud y su actuación en los campos de práctica. Los estudiantes de enfermería no perciben la propia vulnerabilidad ni sus dificultades ante la aproximación de grupos vulnerables durante el proceso de formación.

Conclusión: Aspectos relacionados con la sexualidad, las infecciones de transmisión sexual y las poblaciones vulnerables están presentes en la enseñanza y en la práctica profesional de enfermería. Estos temas responden a las necesidades de la sociedad y a la importancia de intervenir y reflexionar sobre ellos.

\section{Introdução}

A abordagem da vulnerabilidade como termo associado à epidemia do vírus da imunodeficiência humana (HIV) surge na década de 1990 e representa um conjunto de condiçóes que tornam as pessoas suscetíveis às doenças. ${ }^{(1)} \mathrm{A}$ vulnerabilidade está associada à concepção de bem-estar social adotada pelo Estado. ${ }^{(2)}$

Seu conceito pode ser compreendido em três perspectivas, sendo: individual, social e programática. Na representação conceitual da vulnerabilidade leva-se em consideração o componente individual que está associado ao nível de informaçóes que a pessoa sabe/conhece acerca do problema e a capacidade de assimilar e operacionalizar açóes e práticas protetoras ao cotidiano; o componente social está relacionado a fatores disponíveis na sociedade, seja o acesso a informaçóes, serviços, cultura, entre muitos outros, que podem ser de acesso/utilizaçáo do cidadáo; e o componente programático se refere às ações políticas e os serviços de saúde que visam reduzir e controlar as doenças. ${ }^{(3)}$

A epidemia diferencia-se em três fases, sendo a primeira caracterizada apenas pelos infectados pelo HIV - homens homossexuais com alto nível de escolaridade - à época considerados "grupos de risco". $\mathrm{Na}$ segunda fase, foi adotado o conceito de "com- portamento de risco" devido ao aumento da contaminação por uso de drogas injetáveis, atingindo número maior de heterossexuais. A terceira e atual fase, caracterizada pela interiorizaçáo e aumento de casos entre pessoas do sexo feminino e com baixa escolaridade, o conceito adotado passa a ser de "vulnerabilidade". ${ }^{(4)}$ A vulnerabilidade às Infecçôes Sexualmente Transmissíveis (IST) está relacionada a diversos fatores, dentre eles, os socioeconômicos, culturais e comportamentais.

Neste estudo a intençáo está na abordagem do referencial da vulnerabilidade e sua complexidade associada às IST, que abrangem os aspectos individuais, sociais e consequentemente, programáticos, uma vez que se refere às condiçóes de reconhecimento individual das IST, a promoção da saúde, ensino, prevenção e à própria dinâmica das açôes políticas para o controle preventivo-educativo das epidemias.

Assim, estudos sobre essa temática podem contribuir para a compreensão do fenômeno e o desenvolvimento de açôes estratégicas para reduzir esses agravos. Açóes de prevenção com relação às IST visam a redução do número de parceiros sexuais, uso de preservativos, atendimento de saúde imediato ao aparecimento de sinais e sintomas e realização de exames periódicos, o que deve ser abordado e discutido nos cursos de graduação em saúde, sobretudo 
em Enfermagem, partindo do pressuposto que o enfermeiro atua como agente educador e na prática profissional.

O enfermeiro possui papel fundamental nessas açóes, estudos apontam o enfermeiro enquanto promotor de diálogo com adolescentes sobre questôes que envolvem a sexualidade, ato sexual e IST. Informaçóes quanto ao uso do preservativo e os métodos contraceptivos também são ações educativas que compóe o papel do enfermeiro, pois o mesmo através da conscientização contribui na redução dessa problemática. ${ }^{(5)}$ Estudo acerca da realidade profissional da enfermagem frente a problemática da sífilis em gestantes, aponta a importância do enfermeiro no diagnóstico precoce, controle e prevenção através de atividades de intervenção, e tratamento efetivo ao paciente e parceiro sexual. ${ }^{(6)}$

$\mathrm{Na}$ atenção em saúde existem fragilidades em relação a abordagem da sexualidade que envolvem razóes pessoais e contextuais. Os profissionais de saúde ainda percebem temas como a sexualidade um tópico sensível e delicado pertencente à esfera privada. ${ }^{(7)}$ Os cuidados na área da saúde sexual estáo ainda associados a tabus e preconceitos, tanto na formação acadêmica quanto na prática profissional. A sexualidade emerge como alvo de intervenção que necessita da desconstruçáo de representaçóes errôneas sobre gênero e sexo, e que envolve dimensóes biológicas, humanas e sociais que necessitam da integração de novos conhecimentos na formação e desenvolvimento dos profissionais que atuam sobre o cuidado. ${ }^{(8)}$

Reflexôes acerca das vulnerabilidades das populaçóes às doenças, nos leva a entender que a possibilidade de infecçóes pelas IST não estão apenas relacionadas as informaçóes e postura individual, mas a diversos determinantes que vão além da ação patogênica do agente viral específico. ${ }^{(3)}$

As preocupaçóes envoltas no ensino do tema, permeiam a sua trajetória histórica onde o medo, estigmas e tabus ainda estão associados ao ensino da temática nos tempos atuais. $\mathrm{O}$ enfermeiro deve ser preparado para lidar com a identidade de gênero, sensibilidade à sexualidade ao prestar os cuidados, linguagem não estigmatizante, além de vivência em campos de práticas especializados. Sendo assim, al- guns docentes possuem resistência, seja por falta de preparo na sua própria formação quanto das oportunidades ofertadas aos seus alunos em salas de aula ou campos de ensino. ${ }^{(9)}$ A partir dos apontamentos, questiona-se então qual o dito e o não dito no ensino das Infecçôes Sexualmente Transmissíveis em um Curso de Graduação em Enfermagem do Sul do Brasil?

Desta maneira surge como objetivo do estudo analisar o dito e o náo dito no ensino das Infecçóes Sexualmente Transmissíveis em um Curso de Graduação em Enfermagem do Sul do Brasil.

\section{Métodos}

Trata-se de uma pesquisa sócio-histórica, de abordagem qualitativa, com uso de fontes orais e documentais. Foram entrevistados 13 docentes de um curso de graduação em enfermagem de uma Universidade Federal do Sul do Brasil. Através de Catálogos Oficiais produzidos pela instituição, foi possível identificar os departamentos, quadro docente, quadro de disciplinas, ementas e carga horária entre os anos de 1971 a 2004. Posterior a essa data, foram analisadas grades curriculares disponíveis online. Também compuseram a busca documental, um Projeto Político Pedagógico do curso disponível online e três planos de ensino de disciplinas disponibilizadas pelos docentes entrevistados que abordaram ao longo da trajetória do curso a temática em questão.

Os participantes foram escolhidos por meio da técnica de indicação de nomes, denominada snowball. Como critério de inclusão participaram do estudo docentes que ministraram aulas ou tiveram envolvimento na implementação da temática no curso de graduação em enfermagem e de exclusão palestrantes, profissionais de saúde e docentes não vinculados a instituição de ensino.

Os participantes selecionados concordaram em participar do estudo por meio da assinatura do Termo de Consentimento Livre e Esclarecido (TCLE). Os participantes foram identificados pela letra C, correspondente aos Coordenadores do curso, e P, referente aos Professores do curso, seguidas 
de números atribuídos conforme a ordem cronológica de sua participação.

A coleta de dados ocorreu entre os meses de março e abril de 2019, pela autora principal do estudo, e foi realizada por meio de entrevistas com roteiro semiestruturado, registradas com auxílio de um gravador digital. Estas ocorreram conforme a disponibilidade e local de escolha dos participantes (residência, cafeteria, aplicativo de vídeo chamada e salas da própria instituição) com duração média de 40 minutos. Posteriormente foram transcritas e validadas pelos respondentes via correio eletrônico.

Foram respeitados os aspectos éticos conforme recomendaçóes da Resolução n. 466/12 do Conselho Nacional de Saúde, assim como a pesquisa foi aprovada pelo Comitê de Ética envolvendo Seres Humanos sob número do parecer 3.027.667 de 2018.

A análise dos dados fundamentou-se na proposta operativa de Minayo ${ }^{(10)}$ que compreende dois momentos: o primeiro relacionado às determinaçôes fundamentais da pesquisa, mapeado na fase exploratória da investigaçáo; o segundo denominado de interpretativo é o ponto de partida e o ponto de chegada da investigação. $\mathrm{O}$ momento interpretativo foi constituído pela ordenação e classificação dos dados, análise final e relatório. Após transcritas, as entrevistas foram codificadas em unidades de registro e posteriormente por assimilação foram elaboradas as três categorias de análise: (Des)preparo do docente e dos profissionais de saúde para lidar com o tema; (Des)preparo dos estudantes acerca da própria vulnerabilidade às Infecçôes Sexualmente Transmissíveis; Enfoque do currículo do curso de enfermagem com as populaçóes vulneráveis.

\section{Resultados}

Na categoria (Des)preparo do docente e dos profissionais para lidar com o tema, o estudante universitário do curso de graduação em enfermagem faz parte de um contexto em que se enquadra como sujeito vulnerável às IST e futuro profissional de saúde que irá enfrentar essa realidade na sua prática profissional. Abordar a vulnerabilidade do estudante, bem como o seu enfrentamento profissional, implica em tornar temas como sexualidade e as adversidades a ela intrínsecas visíveis, reforçando sua importância no ensino e currículo do curso. As fontes orais do estudo apontam que esse tema está associado a docentes específicos do curso que buscam ampliar espaços e defender a oferta e abordagem desse ensino.

Falta o acolhimento desse aluno de graduação; trazer para dentro do contexto da sala de aula, problematizar, discutir esse tema, sobre as dificuldades enfrentadas pelos estudantes em relação a sua própria sexualidade. Não são dificuldades de acesso à informação. A dificuldade é usar camisinha e perder o parceiro, isso é outra coisa, isso tem a ver com autoestima, com reconhecimento, com auto valoração; não tem a ver com conhecimento técnico, com a orientação ou com informaçóes que eu tenho... (C3)

(...) Várias tentativas são feitas, mas a lógica que a gente trabalha aqui de autonomia das fases, eu acho difícil de fazer isso, acho que a coordenação tenta, mas o professor está ali em uma fase, ele se preocupa muito com aquela temática, ele defende, ai a temática cresce, daqui a pouco ele não está mais, os outros estão preocupados com outras, e batalham... (C4)

Como vou avaliar se o ensino de DST está avançado, se eu perguntar para ti quantos sáo os professores do departamento de saúde pública e da enfermagem realmente envolvidos no fazer de infecção sexualmente transmissivel, vai ser quase zero, se escreve um monte, mas a gente não vê paciente há muito tempo. Essa distância da realidade, ela se reflete pedagogicamente no dia a dia. (P8)

Existe uma vasta gama de assuntos que precisam ser abordados no que tange à temática das IST, pensando nisso, os docentes fazem emergir que eles mesmos se sentem despreparados e possuem resistência em abordar essas questôes com naturalidade. O tema aparece na universidade por meio de temas associados à sexualidade e com muita resistência associada ao próprio universo que abrange e o preparo do professor. 
Pensando no reflexo na educação acerca do tema para a formação do enfermeiro, essas barreiras existentes (medo, estigma, falta de conhecimento, entre outros) entre a temática e o docente traduzidas para o ensino refletem em como os futuros enfermeiros irão relacionar esse conhecimento na prática profissional. Condutas específicas do enfermeiro para o enfrentamento dessa problemática de saúde são essenciais e quando não abordadas se mostram como déficit da abordagem profissional refletindo na atenção em saúde.

Penso que a formação profissional na área da saúde não percebe esse embate (ou pelo menos não o problematiza) e o sentimento, que talvez seja também um mecanismo de proteção do docente, é exatamente voltar para aquele comportamento de que nada está acontecendo, que é uma forma também de se proteger e não enfrentar esse assunto, porque ele vem carregado de posturas morais fortes e, muitas vezes, antagônicas. (C3)

O próprio docente apresenta limitaçóes para abordar o tema, não se sente amparado e entende a dimensão da importância dessa abordagem. Também sente-se responsável pela formação dos futuros enfermeiros, levando em consideração que essa problemática estará no cotidiano de trabalho.

Com relação ao (Des)preparo dos estudantes acerca da própria vulnerabilidade às Infecçóes Sexualmente Transmissíveis, a vulnerabilidade dos estudantes frente às IST, os docentes evidenciam a necessidade de compreender o estudante em toda a sua complexidade de orientação e prática sexual.

E voltado em Paulo Freire: para mudar essa perspectiva, precisa olhar para esse conteúdo e se implicar com cada sujeito-estudante, porque no curso de graduação nós temos estudantes de todas as orientaçôes sexuais, com as mais diversas práticas sexuais, e correndo todos os riscos apesar dos conhecimentos de que dispóem. (C3)

$O$ estudante ele tem medo, normal... medo do que ele ouve, então o que ele conhece não é aquilo que seria a realidade, mas é muito tabu, os estigmas e ele só vai perdendo na medida que ele vai se inserindo e vai vendo que a coisa não é assim exatamente, pode até em algum momento ser pior do que falam, ou imagina, mas ele tem uma responsabilidade, então ele passa gradativamente a perder $o$ medo, e no momento que ele passa a atuar ele passa a perder o medo. (C2)

O estudante de enfermagem, na perspectiva de abordagem das populações vulneráveis, durante a graduação possui alguns espaços de aproximação, dentre eles discussóes sobre diversidade sexual, drogas e atividades voltadas para a atenção básica de saúde. No início da epidemia do HIV, a temática da sexualidade causava muito medo e os docentes tentavam apresentar as questóes que também colocavam os estudantes nesse grupo de vulnerabilidade.

Nâo lembro de nunca ter dado ênfase ao tema. No desenvolvimento das disciplinas ele era estimulado, a participar de grupos, de passeios e visitas a tais locais, e o objetivo era ele ver como é que a coisa funcionava, agora eu acho que se a gente tivesse tido mais tempo, mais disponibilidade até de pessoal, teria sido bem melhor. (C1)

O estudante vai ter contato com a populaçâo de rua. Ele tem contato com a discussão de gênero, com a questão da diversidade sexual, ele tem esse contato, o curso oferta isso, para que ele se sensibilize e que ele busque saber mais... Ele é preparado a partir do momento que o conteúdo é garantido. A primeira coisa que a gente tem que pensar é em que medida que torna esse conteúdo garantido ou não... (C5)

A própria universidade representa um cenário onde possa instigar reflexóes sobre o autocuidado dos estudantes. $\mathrm{O}$ contexto da universidade é cheio de questóes a serem pensadas quando refletimos acerca da saúde dos estudantes, sejam as festas universitárias, desinteresse acerca do tema, ou banalização das consequências que advém das IST.

\section{(...) Quanto ao próprio aluno, o que a própria} instituição ou quem está ensinando saúde está 
cuidando da própria saúde dos alunos ou está os fazendo refletirem sobre a própria saúde (...) Até que o ponto nas festas os alunos estáo se cuidando para prevenir tanto acidente de trânsito, quanto às doenças sexualmente transmissiveis. (P6)

Não existe nessa área nenhum projeto de extensão, que trate das doenças sexualmente transmissiveis. A própria universidade, o próprio grupo de estudantes muitas vezes não se interessam pela forma que é abordado o assunto. É um conteúdo que ele tem um termo teórico, mas ele tem muito de inserção na prática... Ele não se vê parte desse grupo vulnerável, e ai que é o maior risco, porque ele está inserido e não percebe. A gente está vendo muitos alunos jovens, ficando estéreis por doenças transmissiveis... todas essas doenças que estavam extintas ou eram medos sociais, ou estavam negligenciadas... (P4)

Atualmente os estudantes se mostram mais equiparados em conhecimento básico acerca das IST. Docente referência da área coloca que os percebe mais equiparados nessa temática devido ensinamentos no ensino médio, entretanto, os mesmos não se percebem vulneráveis a elas.

Quanto ao Enfoque do currículo do curso de enfermagem com as populaçóes vulneráveis e a sua abordagem no curso de graduação de enfermagem de uma Universidade Federal do Sul do Brasil mostram-se invisibilizadas. O tema é colocado como algo que o curso se sensibiliza a apresentar aos alunos, sendo expostos e apresentados em algumas disciplinas durante os as fases da graduação. É apontada a necessidade de uma política de acompanhamento às populaçóes vulneráveis dentro do âmbito universitário.

Essa população é invisibilizada. Não só no processo de formação da enfermagem, mas no contexto da sociedade como um todo. Está mais vinculado a área de serviço social, especialmente com moradores de rua, que vai recolher o sujeito, que leva para a unidade básica ou para casas de apoio. Mas o serviço de saúde não tem um trabalho especifico voltado para essas pessoas. (C3)
O tema da vulnerabilidade é destacado discursivamente, o curso afirma que faz, se ele é abarcado com toda a sua complexidade pensando em todos os diferentes sujeitos que podem ser considerados populaçóes vulneráveis, eu não sei, mas eu acho que tem uma preocupação, novamente talvez mais de alguns professores do que de outros, eu acho que tem esse interesse, se não de todos, de vários. (C4)

O que pauta se o ensino é ministrado, são as politicas públicas, então a discussão de diversidade de gênero, ela vai ser pautada (...). Nas reformas curriculares é feito uma ampla consulta as populaçóes vulneráveis, se essas populaçóes vulneráveis participam da construção das políticas. Se você pensar em uma politica LGBTQ, como movimentos sociais organizados que tem representatividade, $e$ eles participam da construção de materiais técnicos que orientam os profissionais da saude sobre cuidar, então eles participam. Se for pensar nessa lógica, a disciplina sobre violência, sexualidade no curriculo, onde a diversidade de gênero é transversal, ela aparece. (C5)

Os estudantes entram em contato com essas populaçôes nos diversos cenários teórico-prático em que estão inseridos. $\mathrm{Na}$ visão dos docentes algumas temáticas estão mais associadas às populaçôes vulneráveis, como é o caso de atividades nos Centros de Atenção Psicossocial (CAPS). O curso possui uma preocupação em abordar, entretanto, devido a algumas barreiras, medos e estigmas e algumas ações acabam sendo prejudicadas ou abandonadas.

Eu sei que várias vezes a gente procurou trabalhar com uma questão de saúde dos homens, que também, pode se dizer na área da saúde que é uma população vulnerável... Essa população vulnerável, é aquela questão de como é que tu vai abordar, como você vai chegar nelas... Populaçâo vulnerável acho que tem até mais, porque por exemplo o usuário de droga tem toda aquela questão, não sei como está hoje, mas tinha o "uso seguro", algo assim... as prostitutas, teve até acho que na época desse curriculo na oitava fase, um projeto com prostitutas, então teve algumas iniciativas mais inovadoras, 
mas dentro da assistência primária, eu vou dizer. É difícil porque tem dificuldade ou medo e tem que se empenhar muito, e tem que estar, digamos, amparada. (P6)

A gente vê na obstetricia, mulheres violentadas, vitimas de violência, o tipo de abordagem que muitas vezes é feita, discriminatória, cheia de preconceito, quando o pessoal trans vai em uma consulta, como é que é a abordagem... Tem essa secretaria da diversidade, que é uma coisa importante, inovadora, porque era uma negação total, mas dentro do curso trabalhar algum conteúdo de vulnerabilidade social e esses grupos não, acho que não tem, não se devolve isso. (P4)

Quando traduzido o ensino na questão de vulnerabilidade de diversos grupos das populaçóes acerca das IST, os docentes apontam que precisam estar preparados para atender esses pacientes mais especificamente na atenção básica. Há uma dificuldade em permanecer com projetos de apoio dentro do curso de enfermagem e na abordagem da temática devido ao medo, falta de apoio e despreparo ao lidar com situaçóes de vulnerabilidade.

\section{Discussão}

A sexualidade ganhou visibilidade nos estudos realizados por Freud no início do século XX, e por Michel Foucault na década de 1980, mesmo assim sua abordagem ainda parece estar voltada para características normativas como aspectos biológicos. (11) Apesar dos avanços científicos e tecnológicos das últimas décadas, nota-se que a sexualidade ainda tem impregnada em si mitos, preconceitos e desconhecimentos para muitos indivíduos. Faz parte de um tema repleto de contradiçóes e tabus, que muitas pessoas consideram algo exclusivo para adultos e defendem a ideia de excluir esse tema dos âmbitos de palestras, cursos e currículos escolares, por considerarem-no obsceno. ${ }^{(11,12)}$

Os debates em torno da inclusão e temas na educaçáo escolar relacionados ao corpo e aspectos que o acompanham como a sexualidade, gênero e sexualidades ocorrem desde a década de 1970 . Fortaleceram-se, pois tratam de questóes que evidenciam a transição de fases explícitas do corpo de alunos durante a escolarização. Desta maneira, essas questóes relacionadas à transição do corpo e sua descoberta se fazem importantes no âmbito escolar. Posteriormente, na década de 1980, as demandas que envolviam aspectos sexuais se agravaram com o advento da aids, pois intensificou-se a preocupação pelo aspecto formativo da escola, a Educação Sexual, que passou a ser "oficializada" nos meios normativos educacionais, visando açóes e discussôes que abrangessem sexualidade na escola, prevenção à gravidez precoce, infecção pelo HIV/aids e demais IST (autores colocam que: Gênero e sexualidades são categorias que passaram a ser discutidas somente após a sexualidade. A fim de expressar as diversas possibilidades de vivência da sexualidade, nos dias atuais, a palavra sexualidade é utilizada por muitos(as) estudiosos(as) no plural (sexualidades), evidenciando o fator da diversidade e da pluralidade no que diz respeito à expressão e vivência da sexualidade humana). ${ }^{(13)}$

No Brasil, com relação aos apontamentos acima, surge como Parâmetro Curricular Nacional o tema transversal "Orientação Sexual" cujo objetivo é considerar a sexualidade como algo inerente à vida e àa saúde, englobando o papel social das pessoas, o respeito a si e o outro, discriminaçóes e estereótipos em seus relacionamentos, avanço da aids e da gravidez indesejada na adolescência. ${ }^{(14)}$

As preocupaçóes em torno desse tópico envolvem todo o contexto do ensino médio, pois nesta fase as vivências sexuais se iniciam e se intensificam, os livros pouco relatam sobre as questôes que envolvem as IST e HIV/Aids, estáo voltados para a abordagem biológica da contaminação e não se discute muito de forma aprofundada a prevenção e tratamento. ${ }^{(15)}$ Esse déficit associado à falta de educação sexual pode ser o causador de comportamentos sexuais de risco. ${ }^{(16-18)}$

Desta maneira, a Educação Sexual implica em reeducação da própria sexualidade. Muitos docentes do curso de graduação em enfermagem sentem-se despreparados para lidar com o tema da sexualidade, essa temática está envolta de posiçôes e compor- 
tamentos morais que requerem um olhar atento e envolvem até mesmo o próprio viver e compreender do professor com relação sexualidade. $\mathrm{O}$ tema aparece associado a docentes específicos que buscam abordar em suas aulas esse tópico, e são poucos os docentes engajados em defender a efetivação desse ensino no currículo de enfermagem.

Percebe-se que os docentes sentem dificuldade pessoal em compreender a complexidade da sexualidade humana, pois envolvem aspectos relacionados a posturas, crenças, tabus e valores atribuídos aos relacionamentos e comportamentos sexuais. ${ }^{(19)}$ A formação docente com relação às questôes sociais, culturais e históricas da sexualidade e a sua articulação com as relaçóes de gênero encontra-se fragilizada e para que ocorra a apropriação teórica necessária é necessário que os docentes reconheçam os valores que permeiam suas condutas, se sintam sensibilizados quanto à existência da diversidade sexual e reflitam acerca dos princípios democráticos que devem ser alcançados. ${ }^{(20)}$

A docência universitária pressupooe que o docente esteja em constante aprendizado, para que seu trabalho ocorra de maneira contextualizada e atualizada, a fim de auxiliar o estudante a estabeler relaçóes entre o conhecimento e a área de atuação profissional. ${ }^{(21)}$ É válido colocar no contexto de autonomia universitária, a liberdade docente na sua prática pedagógica em ministrar tópicos e conteúdos dentro das disciplinas curriculares. Desta maneira fazendo uma articulação com o apresentado nas falas dos participantes, a autonomia docente e a aproximação docente com suas áreas de conhecimento interferem na efetivação do ensino de maneira subjetiva, ou seja, conteúdos de maior dominância dos docentes irão se sobressair em um currículo ou na gama de disciplinas.

Essa preocupação acerca da autonomia e área de estudo/pesquisa do professor nos cerca de reflexóes acerca dos currículos de enfermagem e suas prioridades educacionais. Faz-se importante refletir sobre a interdisciplinaridade e multidisciplinaridade de um currículo em que atenta todas as necessidades da população. Considerando a temática IST, a mesma perspassa diversas etapas da vida e atinge todas as faixas etárias.
A articulação do conhecimento acerca da sexualidade, IST e as populaçóes vulneráveis no ensino da enfermagem irá refletir na prestação do cuidado na prática profissional em saúde. ${ }^{(20)}$ Desta maneira as instituiçóes de ensino superior se mostram importantes na apresentação e efetivação do ensino assim como na sensibilização do estudante em melhorar sua própria educação com relação a essa temática. É colocado que o curso apresenta ao estudante diversas populaçóes vulneráveis ao longo da graduação, entretanto, a aproximação com elas é de difícil manejo e acesso.

Apesar do alto grau de escolaridade associado aos universitários, o conhecimento acerca das IST e questôes relacionadas à saúde reprodutiva por muitas vezes aparece escasso, ${ }^{(22,23)}$ o que pode levar a um despercebimento dos riscos que os tornam vulneráveis as IST e os levam a negligenciar a importância de comportamentos protetivos. É entendido que a busca pelo cuidado de enfermagem de maneira igualitária, para diferentes sexos, relaciona-se à assexualização do sujeito cuidado. Essa prática requer uma descaracterização do individuo, tanto daquele que está cuidado quanto daquele que está sendo cuidado. Também existe a dificuldade em cuidar com ética, respeito e comprometimento, desconsiderando essa dimensão da vida que não é apenas biológica, mas evidentemente social e cultural. ${ }^{(3)}$

Com relação aos estudantes das universidades, serem em predominância adolescentes e jovens, esse público está em maior número no que se diz a vulnerabilidade frente às IST, e um dos motivos é a necessidade de descoberta de um tópico que é tido como tabu, o sexo. ${ }^{(15)}$

A falta de conhecimento acerca do uso de métodos preventivos deixa os jovens expostos a riscos. Desta maneira, faz-se importante adotar medidas de conscientização e elaboração de estratégias de educação em saúde para abordagem dessa temática na população jovem. As ações de educação em saúde que aborda temas como a sexualidade, métodos contraceptivos, IST e HIV/Aids são ferramentas fundamentais na promoção ao acesso de informaçóes adequadas que favoreçam e promovam atitudes de autocuidado em relação à prática sexual. ${ }^{(24,25)}$

Pesquisas realizadas com o público universitário evidenciam que a prevenção está relacionada ao uso 
de preservativo, percepção de risco pessoal e conduta sexual preventiva, demonstram ainda que os universitários da área da saúde possuem alto nível de conhecimento acerca das infecçóes de cunho sexual e dos métodos de prevenção, entretanto o conhecimento não é suficiente para que os mesmos reduzam atividades sexuais de risco. ${ }^{(26-28)}$

Esses dados no fazem refletir sobre algo que vai além da oferta do ensino e informaçôes, pois os estudantes universitários possuem o conhecimento necessário para adotar medidas preventivas, entretanto muitas vezes, não as colocam em prática. Observase nesse estudo que as dificuldades no ensino estão na possibilidade de aproximaçáo ao estudante para manter um diálogo educativo aberto, para tanto há a necessidade de o professor ter um entendimento dos aspectos do corpo, do gênero e da sexualidade. $\mathrm{O}$ que denota, neste estudo, uma grande fragilidade. Assim, tanto o docente quanto o discente e, o futuro sujeito realizador da educação em saúde, o profissional; dependem do autoconhecimento e da cultura que vivenciam ou vivenciaram na sua educação familiar, básica e atual de vida em sociedade.

O estudante jovem, em seu contexto de universitário, enquanto público vulnerável na visão dos docentes não se sensibilizam ou não se veem vulneráveis. $\mathrm{Ou}$ seja, existe uma dificuldade em relacionar a sexualidade e a vulnerabilidade do próprio estudante em sala de aula. O estudante com o avançar do curso aumenta seu leque de conhecimento acerca do tema como também tem contato nos campos de prática com os grupos vulneráveis às IST.

Para o público universitário, muitas vezes jovens adultos, que iniciaram a vida sexual há pouco tempo, o conceito de vulnerabilidade parece ser algo distante. Estudo realizado com esse público coloca que questôes que envolviam a vulnerabilidade pessoal com relação as IST/HIV/aids sob a ótica dos participantes coloca como sendo vulnerável o “outro", pois ser vulnerável está associado ao estilo de vida sexual de promiscuidade, desregramento e comportamentos não aceitos moralmente, o que justificaria uma infecção/contaminação por IST. ${ }^{(29)}$

A OMS reitera que a modificaçáo do panorama de infecção pelas IST/HIV versus redução da sua transmissão relaciona-se às práticas efetivas de prevenção. Nesse sentido, as estratégias preventivas incluem a educação sexual abrangente, a aquisição de noçóes sobre as IST/HIV, corpo e gênero, além do aconselhamento sobre sexo seguro e sobre as mudanças de comportamento, os quais exigem construção e reconstrução de saberes. Esses aspectos remetem à sexualidade, devendo ser alvo das práticas profissionais de saúde. ${ }^{(30)}$

Diante disto, as açóes educativas no campo da saúde permitem que o indivíduo reflita sobre sua condição real de vulnerabilidade e se sensibilize a incorporar atitudes saudáveis com relação a sua prática sexual. Essas ações, na visão dos docentes, fazem parte do cotidiano do profissional de enfermagem, sendo necessária a abordagem desse tema na graduação para que os estudantes na posição de futuros profissionais estejam aptos e capacitados para lidar e intervir.

As ações de saúde sexual e reprodutiva são amplas e abrangem a assistência clínica, o aconselhamento e as atividades educativas. Fazem parte dessa pauta atendimento pré-natal, parto e puerpério, assistência humanizada ao aborto conforme previsto em Lei, atendimento com foco nas IST e outras afecçóes do aparelho reprodutor, envolvendo todas as populaçóes, sendo elas lésbicas, gays, bissexuais, travestis, transexuais, transgêneros ou intersexuais (LGBTI+) e outras situações de vulnerabilidade. Diante desse tema abrangente, os cuidados devem ser ofertados sem distinção de raça, crença religiosa, orientação sexual e idade. ${ }^{(31)}$ Desta forma, a prática da enfermagem é essencial para ações de educação em saúde, pois favorece a abertura para o diálogo, bem como atua diretamente na promoção e prevenção da qualidade de vida sexual. Essas açóes ocorrem durante o curso de graduação em enfermagem e existe uma interação de saberes entre os docentes e estudantes.

\section{Conclusão}

A partir dos resultados encontrados, observa-se que os docentes apresentam dificuldades em lidar com a temática e conduzi-la como conteúdo em suas disciplinas, devido suas próprias limitaçôes para lidar 
com um tema tão complexo. Outros, ao contrário podem ser considerados "experts" e incentivadores do ensino e inserção da temática. Um aspecto importante nesta discussão é a compreensão de que os estudantes também estáo em condição de vulnerabilidade diante das IST, devido a estarem no papel de futuro profissionais e educadores e não se verem com chances de contrair alguma IST. Apesar da abordagem do tema ser de forma transversal ou paralela em algumas disciplinas e campos de prática, reforça-se a importância da abordagem das IST, devido a multiplicada de papéis do enfermeiro no contexto da saúde, como educador, profissional e próprio ser vulnerável. Neste sentido, entende-se que esta discussão não se esgota neste manuscrito e deve servir de alerta para os educadores, coordenadores de cursos de graduação em enfermagem e mesmo os docentes dos cursos, para que náo desvalorizem a importância deste conteúdo, como obrigatório.

\section{Agradecimentos}

À Coordenação de Aperfeiçoamento de Pessoal de Nível Superior (CAPES; bolsa de mestrado para Stéfany Petry). Ao Conselho Nacional de Desenvolvimento Científico e Tecnológico (CNPq; bolsa de doutorado para Stéfany Petry).

\section{Colaborações}

Petry S, Padilha MI, Bellaguarda MLR, Vieira AN e Neves VR contribuíram com a concepção do estudo, análise e interpretação dos dados, redação do artigo, revisão crítica relevante do conteúdo intelectual e aprovação da versão final a ser publicada.

\section{Referências}

1. Malagón-Oviedo RA, Czeresnia D. The concept of vulnerability and its biosocial nature. Interface (Botucatu). 2015;19(53):237-49.

2. Carmo ME, Guizardi FL. The concept of vulnerability and its meanings for public policies in health and social welfare. Cad. Saúde Pública. 2018; 34(3):e00101417.
3. Sevalho $\mathrm{G}$. The concept of vulnerability and health education based on the theory laid out by Paulo Freire. Interface (Botucatu). 2018; 22(64):177-88.

4. Silva AF, Cueto M. HIV/AIDS, its stigma and history. Hist Cienc Saude Manguinhos. 2018; 25(2):3114.

5. Junqueira MS, Silva EV, Santos JR, Silva PP, Cavalcanti IF, Silva FP. Infecções sexualmente transmissíveis: atuação do enfermeiro nas ações educativas na adolescência. Rev Saúde - UNG-Ser. 2016;10(1):128.

6. Rodrigues AR, Silva MA, Cavalcante AE, Moreira AC, Mourão Netto JJ, Goyanna NF. Practice of nurses in the monitoring of syphilis in primary care. Rev Enferm UFPE Online. 2016;10(4):1247-55.

7. Ferreira SM, Gozzo T0, Panobianco MS, Santos MA, Almeida AM. Barriers for the inclusion of sexuality in nursing care for women with gynecological and breast cancer: perspective of professionals. Rev Latinoam Enferm. 2015;23(1):82-9.

8. Lourenço H. 0 papel do enfermeiro na sexualidade do cidadão com problemas no seu continuum de saúde. Rev Port Enferm Saúde Mental. 2020; (23):6-8.

9. Rowniak S, Selix N. Preparing nurse practitioners for competence in providing sexual health care. J Assoc Nurses AIDS Care. 2016; 27(3):355-61.

10. Minayo MC. 0 desafio do conhecimento: pesquisa qualitativa em saúde. São Paulo: Hucitec; 2014.

11. Saraswat A, Weinand J, Safer J. Evidence supporting the biologic nature of gender identity. Endocrine Pract. 2015; 21(2):199-204.

12. Spurlock DR, Patterson BJ, Colby N. Gender Differences and Similarities in Accelerated Nursing Education Programs: Evidence of Success from the New Careers in Nursing Program. Nurs Educ Perspect. 2019; 40(6):343-51.

13. Brabo TS, Silva ME, Maciel TS. Gender, sexuality and education: educational policies scenario on the young and adolescents sexual and reproductive rights. Praxis Educ. 2020;15:1-21.

14. Brasil. Parâmetros curriculares nacionais: Orientação Sexual. Secretaria de Educação Fundamental. - Brasília: MEC/SEF; 1997. $126 p$.

15. Almeida RA, Corrêa RG, Rolim IL, Hora JM, Linard AG, Coutinho NP, et al. Knowledge of adolescents regarding sexually transmitted infections and pregnancy. Rev Bras Enferm. 2017;70(5):1033-9.

16. Silva AT, Jacob MH, Hirdes A. The knowledge of high school teenagers about STD/AIDS in southern Brazil. Aletheia. 2015; (46):34-49.

17. Sá MI, Silva MT, Almeida D, Vieira B, Lima T, Conde C, et al. Sexually transmitted diseases and risk factors in adolescent and young girls: data from a youth attendance center. Nascer Crescer. 2015;24(2): 649.

18. Araújo LF, Lôbo CJC, Santos JVO, Sampaio AVC. Psychosocial perceptions of persons with hiv about knowledge of aids. Rev Colomb Psicol. 2017; 26(2):219-30.

19. Miranda JR. Sexual education and sexualities: reflections about Extension actions in the training of teachers. Extensio: Rev Eletr Extensão. 2018;15(28):168-81.

20. Santos SMP, Freitas JLGS, Freitas MIF. The sexuality scripts constructed by nurses and an interface with attention of sexually transmited infection/HIV. Esc Anna Nery. 2019; 23(4):e20190078.

21. Bittencourt RL, Silva RG. Contributions of the research for professional teacher development in the perspective of the Coordinators of the Bachelor's Courses. Rev Inter Educ Sup. 2020;6:1-19. 
22. Fonte VR, Spindola T, Francisco MT, Sodré CP, André NL, Pinheiro $\mathrm{CD}$. Young university students and the knowledge about sexually transmitted infections. Esc Anna Nery. 2018; 22(2):e20170318.

23. Gräf DD, Mesenburg MA, Fassa AG. Risky sexual behavior and associated factors in undergraduate students in a city in Southern Brazil. Rev Saúde Pública. 2020; 54:41.

24. Pereira JC, Barbosa LU, Henriques AH, Araújo PM, Muniz M, Melo EC, et al. Health education with school adolescents about sexuality and sexually transmitted infection: an experience report. REAS/EJCH. 2019; 29:1-6.

25. Genz N, Meincke SM, Carret ML, Corrêa AC, Alves CN. Sexually transmitted diseases: knowledge and sexual behavior of adolescents. Texto Contexto Enferm. 2017; 26(2):e5100015.

26. Castro EL, Caldas TA, Morcillo AM, Pereira EM Velho PE. Awareness and education regarding sexually transmitted diseases among undergraduate students. Ciênc Saúde Coletiva. 2016; 21(6):1975-84.
27. Cardoso BC, Mesquita EB, Costa GS, Junior JA, Goiano PD, Ferreira TR. The knowledge of young people under the prevention of hiv/aids And other dsts. Braz J Surg Clin Res. 2017;20(2):80-3.

28. Petry S, Padilha MI, Kuhnen AE, Meirelles BH. Knowledge of nursing student on the prevention of sexually transmitted infections. Rev Bras Enferm. 2019;72(5):1145-52.

29. Silva SP, Silva TB, Rocha TA, Guisande TC, Cardoso AM, Gomes JL, et al. Knowledge and vulnerability representations of STD / HIV / AIDS by college students. ID on line. Rev Psicol. 2016;10(31):25-42.

30. World Health Organization (WHO). Global health sector strategy on sexually transmitted infections 2016-2021. Geneva: WHO; 2016. [cited 2021 Jan 25]. Available from: https://apps.who.int/iris/bitstream/ handle/10665/246296/WH0-RHR-16.09-eng.pdf?sequence=1 .

31. Mansh M, Garcia G, Lunn MR. From patients to providers: changing the culture in medicine toward sexual and gender minorities. Acad Med. 2015;90(5):574-80. 